\title{
Baseline Sensitivity of Botrytis cinerea Isolates from Strawberry to Isofetamid Compared to other SDHls
}

\author{
Adrian I. Zuniga, Michelle S. Oliveira, Carolina S. Rebello, and Natalia A. Peres ${ }^{\dagger}$ \\ University of Florida, Gulf Coast Research and Education Center, Wimauma, FL 33598
}

\begin{abstract}
Succinate dehydrogenase inhibitors (SDHIs) are the fungicides most commonly used to control Botrytis fruit rot on commercial strawberry in Florida. The medium-to-high risk of selection of resistance in the causal agent Botrytis cinerea is a threat to the efficacy of this fungicide group. In this study, we characterized the sensitivity of $B$. cinerea to the SDHI isofetamid, evaluated the $\mathrm{SdhB}$ gene mutation associated with resistance, and monitored resistance frequencies to five SDHI fungicides for two consecutive seasons. $\mathrm{EC}_{50}$ values of 70 isolates were obtained using the spiral gradient dilution (SGD) method and averaged $0.098 \mu \mathrm{g} / \mathrm{ml}$ of isofetamid. $\mathrm{EC}_{50}$ averages of 3.04 and $>500.00 \mu \mathrm{g} / \mathrm{ml}$ were obtained for isolates with the N230I and P225F mutations indicating moderate and high resistance to isofetamid, respectively. A total of $565 \mathrm{~B}$. cinerea isolates collected during 2015-2016 and 2016-2017 seasons from strawberry nurseries and Florida production fields were evaluated using conidial germination

assays. Results for the first season showed resistance frequencies of $95,33,21,25$, and $0 \%$ to boscalid, penthiopyrad, fluopyram, benzovindiflupyr, and isofetamid, respectively. The respective resistance frequencies for the following season were $91,95,44,27$, and $1.3 \%$. Only three isolates were found to be moderately resistant to isofetamid during the second season, and the mutation N230I was identified after sequence analysis. These isolates were confirmed to be resistant to isofetamid in fruit assays with disease incidence of 55.6 to $77.0 \%$; however, the conidial production of the isolates was inhibited by an average of $83.9 \%$. In general, isofetamid efficacy was higher than the other evaluated SDHIs, but a slight increase in resistance frequencies was observed in our study.

Keywords: BFR, fungi, fruit, small fruits, disease management, fungicide resistance
\end{abstract}

Botrytis cinerea is the causal agent of Botrytis fruit rot (BFR), one of the most significant diseases of strawberry in the United States and worldwide (Mertely et al. 2018). During the strawberry season in Florida, temperatures ranging from 15 to $25^{\circ} \mathrm{C}$ with leaf wetness greater than 13 consecutive hours that are optimal for BFR development are common (Bulger et al. 1987). The infection starts as small, hard necrotic spots that can occur on fruit stem and flower parts like petals. Under favorable conditions, the rotting lesions can be entirely covered with masses of conidia that can rapidly spread through the field causing significant yield losses (Williamson et al. 2007). BFR incidence higher than $50 \%$ has been reported on fruit harvested from nontreated plots (Cordova et al. 2015), indicating the importance of an effective disease management program.

BFR management in Florida's commercial fields relies strongly on the use of fungicides. Traditional calendar-based programs consist of protective weekly applications of multisite fungicides such as captan or thiram throughout the season starting after plant establishment with applications of single-site fungicide applications during periods of peak bloom if weather conditions favor BFR development (Legard et al. 2005). This management approach can result in more than 20 applications in a season, many of which may be unnecessary. Cordova et al. (2017a, b, 2018) showed that strawberry growers following the Strawberry Advisory System (StAS) may reduce the number of fungicide applications to manage BFR by approximately $50 \%$ with no harm to yield or disease suppression. The high number of fungicide applications, besides increasing costs, also increase the selection pressure for resistant

${ }^{\dagger}$ Corresponding author: N. A. Peres; nperes@ufl.edu

Funding: This project was partially funded by the Florida Strawberry Research and Education Foundation and the United States Department of Agriculture, National Institute for Food and Agriculture (USDA-NIFA) Specialty Crop Research Initiative (\#2014-51181-22377).

The author(s) declare no conflict of interest.

Accepted for publication 8 November 2019.

(C) 2020 The American Phytopathological Society
B. cinerea populations. Furthermore, this selection might occur at the nursery level, with the use of nontarget BFR sprays to manage other diseases (Oliveira et al. 2017).

$B$. cinerea is considered a high-risk pathogen for the development of fungicide resistance because of its polycyclic life cycle, profuse sporulation, broad host range, and high genetic variability (Fernández-Ortuño et al. 2012; Veloukas et al. 2014). This variability makes the pathogen complex and resistant to a vast number of registered fungicides within the succinate-dehydrogenase inhibitor (SDHI), quinone-outside inhibitor (QoI), anilinopyrimidine (AP), and hydroxyanilide (Hyd) fungicide groups (Amiri and Peres 2014; Kumari et al. 2014). In past years, the SDHI fungicides have become an important and effective tool for BFR control (Hu et al. 2016). The SDHIs are the group incorporating new broad-spectrum compounds in the market most rapidly. They have the specific function of inhibiting the pathogen mitochondrial respiration by targeting the ubiquinone-binding pocket in the mitochondrial respiratory complex II or SDH, compromising SDH-A (flavoprotein), SDH-B (iron-sulfur protein), and SDH-C and D (two membrane-anchored proteins) (Hu et al. 2016; Sierotzki and Scalliet 2013).

Regardless of the SDHIs high fungicide efficacy, these fungicides are classified as having a medium-to-high risk of resistance (Amiri et al. 2014; FRAC 2017). B. cinerea resistance to SDHI fungicides has been associated with genetic modifications in the SDH subunits $\mathrm{B}, \mathrm{C}$, and $\mathrm{D}$. The most frequent and common mutations are in the SDH-B, H272R, and H272Y, the result of the histidine replacement at codon 272 by arginine and tyrosine, respectively. A less common mutation of the same codon is $\mathrm{H} 272 \mathrm{~L}$, replacing histidine for leucine. Other mutations described in the subunit B are N230I, with the replacement of asparagine by isoleucine at codon 230, and $\mathrm{P} 225 \mathrm{~F}$, P225L, and P225T, where genetic modification occurs at codon 225 with the substitution of proline by phenylalanine, leucine, and threonine, respectively (Fernández-Ortuño et al. 2012; Veloukas et al. 2014).

The mutations mentioned above are responsible for conferring different levels of resistance or phenotypes to SDHI fungicides on $B$. cinerea. In the case of boscalid, the first SDHI fungicide released in Florida in 2003, and penthiopyrad, released in 2012, moderate to very high resistance can be observed in $B$. cinerea isolates with H272R/Y, N230I, and P225F mutations. Moreover, only N230I 
and $\mathrm{P} 225 \mathrm{~F}$ have been reported to confer high to very high resistance on fluopyram, one of the newer SDHI fungicides, released in 2015 (Amiri et al. 2014).

Isofetamid is the newest SDHI released for use on strawberry, but resistance has not yet been investigated. Piqueras et al. (2014) demonstrated the high efficacy of isofetamid for control of $B$. cinerea on grape. Isofetamid is also used on berries, lettuce, turfgrass, and rapeseed to control diseases caused by Botrytis and Sclerotia spp. (Jeanmart et al. 2016).

Amiri et al. $(2013,2014)$ showed that $80 \%$ of the $B$. cinerea isolates from strawberry fields were resistant to boscalid and that there was rapid selection of resistance to penthiopyrad, which indicates the importance of a periodic resistance evaluation of old and newly registered fungicides from the SDHI group. Thus, the objectives of this study were to (i) determine the baseline sensitivity of $B$. cinerea isolates collected from Florida strawberry fields to isofetamid; (ii) identify the mutation(s) within the $\mathrm{SdhB}$ subunit conferring resistance to isofetamid; and (iii) monitor the frequency of fungicide resistance among strawberry $B$. cinerea isolates from nurseries and Florida production fields to boscalid, penthiopyrad, fluopyram, benzovindiflupyr, and isofetamid.

\section{Materials and Methods}

B. cinerea isolate collection. Seventy $B$. cinerea isolates collected prior to isofetamid registration for strawberry in 2015 were selected to establish the baseline sensitivity for isofetamid (Table 1). Isolates were collected over a period of 8 years from 2001 to 2013 from symptomatic strawberries produced in different locations in Florida and were preserved in glycerol as conidial suspensions at the Gulf Coast Research and Education Center (GCREC) in Wimauma, FL at $-80^{\circ} \mathrm{C}$. To revive the isolates, a small portion of the suspension was transferred to HA medium (Leroch et al. 2013).

Twelve isolates of $B$. cinerea previously characterized for boscalid sensitivity and their associated mutation in the subunit B of the SDH (Amiri et al. 2014) were characterized for isofetamid sensitivity in this study as described in the section below (Table 2).

For the monitoring of SDHI sensitivity, 565 isolates of $B$. cinerea were collected from symptomatic strawberry fruit and detached leaves from transplants during two consecutive seasons. In the 2015-2016 strawberry season, 141 isolates were recovered from symptomatic fruit produced in five different commercial strawberry fields in Hillsborough County, Florida. During the same season, 188 isolates were obtained from transplants from 12 nurseries: five from Nova Scotia, one from Ontario, and one from Quebec in Canada, three from North Carolina, and two from California in the United States. In the 2016-2017 season, 166 isolates were collected from four commercial fields in Florida and 70 isolates from transplants grown in one strawberry nursery in Nova Scotia, Canada.

Isolates recovered from symptomatic fruit were obtained by vertically cutting the fruit in half to transfer a small piece of infected tissue to HA medium. Isolates from strawberry transplants were recovered following the leaf assay protocol of Oliveira et al. (2017).

Baseline sensitivity of $B$. cinerea isolates to isofetamid and phenotypic characterization. Sensitivity of isolates to isofetamid (Kenja 400SC, SummitAgro, NC) was determined by obtaining $\mathrm{EC}_{50}$ values with the spiral gradient dilution (SGD) method previously developed by Förster et al. (2004) and modified by Amiri et al. (2013). HA medium was used instead of $2 \%$ malt extract agar for incubation of isolates prior to preparation of conidial suspensions. Using the spiral gradient endpoint (SGE) software (Spiral System, Autoplate 4000 model; Spiral Biotech), three stock concentrations were calculated that would correspond to three potential $\mathrm{EC}_{50}$ ranges based on the molecular weight of the fungicide. The three ranges of concentration used were (i) 0.004 to 0.697 , (ii) 0.290 to 44.355 , and (iii) 5.791 to $887.096 \mu \mathrm{g} / \mathrm{ml}$. Stock concentrations were prepared with sterile deionized water and stored at $4{ }^{\circ} \mathrm{C}$. $\mathrm{EC}_{50}$ values for the baseline sensitivity of isofetamid were obtained using the two lower stock concentrations and the assay was performed twice.

For the phenotypic characterization to isofetamid of isolates harboring the $\mathrm{P} 225 \mathrm{~F}$ mutation, the experiment was performed twice using the highest concentration range; whereas for sensitive isolates and isolates harboring $\mathrm{H} 272 \mathrm{R} / \mathrm{Y}$ and N230I mutations, the experiment was performed four times using the remaining two concentration ranges. The $\mathrm{EC}_{50}$ values were used to classify the isolates in three different sensitivity phenotypes: sensitive (S), moderately resistant (MR), and highly resistant (HR) with $\mathrm{EC}_{50}$ values below $1 \mu \mathrm{g} / \mathrm{ml}$, between 1 and $5 \mu \mathrm{g} / \mathrm{ml}$, and greater than $5 \mu \mathrm{g} / \mathrm{ml}$, respectively.

Sensitivity of $\boldsymbol{B}$. cinerea isolates to SDHI fungicides. Isolates collected during the two strawberry seasons were analyzed for SDHI

Table 1. Botrytis cinerea isolates used to determine isofetamid baseline sensitivity

\begin{tabular}{lll}
\hline Year $^{\mathbf{y}}$ & \multicolumn{1}{c}{ Origin } & \multicolumn{1}{c}{ Isolates $^{\mathbf{z}}$} \\
\hline 2001 & - & $01-36,01-37$ \\
2003 & Monticello & $03-37$ \\
2005 & Dover & $05-25,05-28,05-29,05-30$ \\
2008 & Balm & $08-96,08-98,08-100$ \\
2010 & Balm & $10-31,10-39,10-40$ \\
2010 & Lake Wales & $10-36,10-38$ \\
2010 & Dover & $10-41$ \\
2011 & Dover & $11-07,11-08,11-09,11-10$ \\
2011 & Plant City & $11-20,11-106,11-109,11-111,11-350$ \\
2011 & - & $11-45,11-48,11-55,11-57$ \\
2012 & Plant City & $12-20,12-50,12-51,12-248,12-249,12-345$, \\
& & $12-346,12-347,12-348$ \\
2012 & Dover & $12-84,12-85,12-86,12-93,12-95$ \\
2012 & Balm & $12-176,12-178$ \\
2012 & Floral City & $12-320,12-321,12-322$ \\
2012 & Wimauma & $12-384,12-385,12-386$ \\
2012 & Riverview & $12-428,12-429,12-430$ \\
2013 & Balm & $13-03,13-15,13-16,13-17$ \\
2013 & Plant City & $13-152,13-153,13-154,13-155,13-184,13-185$, \\
& & $13-186,13-188$ \\
2013 & Floral City & $13-390,13-391,13-392,13-417$ \\
\hline
\end{tabular}

y Year of collection. All isolates were collected from different cities in Florida prior to isofetamid registration.

${ }^{\mathrm{z}}$ Isolates from culture collection of the Gulf Coast Research and Education Center, University of Florida, Wimauma, FL.

Table 2. Phenotypic characterization of succinate dehydrogenase subunit B $(\mathrm{SdhB})$ mutations to isofetamid

\begin{tabular}{|c|c|c|c|c|}
\hline \multirow[b]{2}{*}{ Genotype $^{\mathrm{z}}$} & \multirow[b]{2}{*}{ Isolate } & \multirow{2}{*}{$\frac{\text { Boscalid }^{\mathrm{x}}}{\text { Phenotype }}$} & \multicolumn{2}{|c|}{ Isofetamidy } \\
\hline & & & $\mathbf{E C}_{50}$ & Phenotype \\
\hline \multirow[t]{2}{*}{ WT } & $11-45$ & HS & 0.18 & $S$ \\
\hline & $12-221$ & HS & 0.30 & S \\
\hline \multirow[t]{4}{*}{$\mathrm{H} 272 \mathrm{R}$} & $12-241$ & $S$ & 0.22 & $S$ \\
\hline & $11-67$ & MR & 0.30 & S \\
\hline & $10-35$ & HR & 0.19 & $\mathrm{~S}$ \\
\hline & $12-332$ & HR & 0.26 & S \\
\hline $\mathrm{H} 272 \mathrm{Y}$ & $12-65$ & VHR & 0.01 & S \\
\hline \multirow[t]{5}{*}{ N230I } & $12-450$ & VHR & 1.46 & MR \\
\hline & $12-255$ & HR & 4.79 & MR \\
\hline & $17-94$ & - & 1.71 & MR \\
\hline & $17-111$ & - & 3.52 & MR \\
\hline & $17-222$ & - & 3.70 & MR \\
\hline \multirow[t]{3}{*}{$\mathrm{P} 225 \mathrm{~F}$} & $11-62$ & VHR & $>500.00$ & HR \\
\hline & $12-355$ & VHR & $>500.00$ & HR \\
\hline & $12-374$ & VHR & $>500.00$ & HR \\
\hline
\end{tabular}

${ }^{x}$ Phenotype of the $\mathrm{SdhB}$ mutations conferring different levels of resistance on Botrytis cinerea isolates to boscalid according to Amiri et al. (2014). HS (highly sensitive), S (sensitive), MR (moderately resistant), HR (highly resistant), and VHR (very highly resistant). Isolates 12-241 and 12-332 showed in this study a substitution of histidine by arginine at codon 272 , different from previously reported by Amiri et al. (2014).

y Phenotypes for isofetamid were determined based on $\mathrm{EC}_{50}$ values obtained in this study. $\mathrm{S}=$ sensitive $(<1 \mu \mathrm{g} / \mathrm{ml}), \mathrm{MR}=$ moderately resistant $(1$ to 5 $\mu \mathrm{g} / \mathrm{ml})$, and $\mathrm{HR}=$ highly resistant $(>5 \mu \mathrm{g} / \mathrm{ml})$.

${ }^{\mathrm{z}}$ Mutations in the subunit $\mathrm{B}$ of the SDH complex. WT = wild type. 
sensitivity based on a conidial germination assay. After incubation of the isolates on HA for 6 to 7 days, individual conidial suspensions of $10^{6}$ spores $/ \mathrm{ml}$ were prepared using a hemacytometer. Petri dishes (15 cm diameter) containing yeast bacto-acetate agar (YBA) (10 $\mathrm{g} /$ liter bacto-peptone, $20 \mathrm{~g} /$ liter sodium acetate, $10 \mathrm{~g} /$ liter yeast extract, $15 \mathrm{~g} /$ liter agar) were divided into 30 rectangles measuring $1.5 \times 2.0 \mathrm{~cm}$, allowing the testing of 30 isolates per plate. Using a graduated $10-\mu l$ pipette, two $7-\mu 1$ drops of conidial suspension were placed diagonally in each space.

YBA medium was amended with discriminatory doses of 1 or $5 \mu \mathrm{g} / \mathrm{ml}$ of penthiopyrad (Fontelis, DuPont, Wilmington, DE), 2 or $5 \mu \mathrm{g} / \mathrm{ml}$ of fluopyram (Luna Privilege, Bayer CropScience, Research Triangle Park, NC), and 2 or $5 \mu \mathrm{g} / \mathrm{ml}$ of boscalid (Endura, BASF, Research Triangle Park, NC) each. These doses had been previously determined by Amiri et al. (2013) to differentiate isolate sensitivity to each respective fungicide, and the YBA medium was chosen based on Weber and Hahn (2011). Doses for benzovindiflupyr (provided from Syngenta Crop Protection for experimental use) and isofetamid (Kenja 400SC, SummitAgro, NC) were 1 or $5 \mu \mathrm{g} / \mathrm{ml}$, each. Nonamended YBA medium was used as a control. All plates were incubated at $23^{\circ} \mathrm{C}$ for 18 to $24 \mathrm{~h}$, and evaluation of conidial germination was based on a method developed by Weber and Hahn (2011) to classify isolates as sensitive (S), moderately resistant (MR), or highly resistant (HR). The percentage of resistant isolates for each fungicide and multifungicide resistance among the SDHIs tested were determined considering MR and HR isolates compared with the total number of isolates. The assay was performed twice and the combination of one plate per isolate/fungicide-concentration was used.

Characterization of $\mathrm{SdhB}$ mutations in resistant isolates of B. cinerea. Twenty-three $B$. cinerea isolates resistant to SDHIs collected in the 2015-2016 and 2016-2017 strawberry seasons were grown on HA medium at $23^{\circ} \mathrm{C}$ for 5 to 7 days. Mycelium from each isolate was collected and DNA extraction was performed using FastDNA Kit (MP Biomedicals).

The primers BcSdhB-F1 (Amiri et al. 2014) and IpBecEnd2 (Leroux et al. 2010) were used to amplify a fragment ( $850 \mathrm{bp}$ ) of the $\mathrm{SdhB}$. Polymerase chain reaction (PCR) was conducted on $25-\mu 1$ volume containing $14.6 \mu \mathrm{l}$ of molecular water, $5 \times$ buffer, $1.5 \mathrm{mM}$ $\mathrm{MgCl}_{2}, 0.2 \mathrm{mM}$ dNTPS, $0.2 \mu \mathrm{M}$ each primer $(10 \mathrm{mM}), 2$ units Taq polymerase, all from Promega Corp, and $20 \mathrm{ng} / \mu 1 \mathrm{DNA}$, following the same parameters described by Amiri et al. (2014). PCR products were sequenced at Genewiz in New Jersey, U.S.A. The software

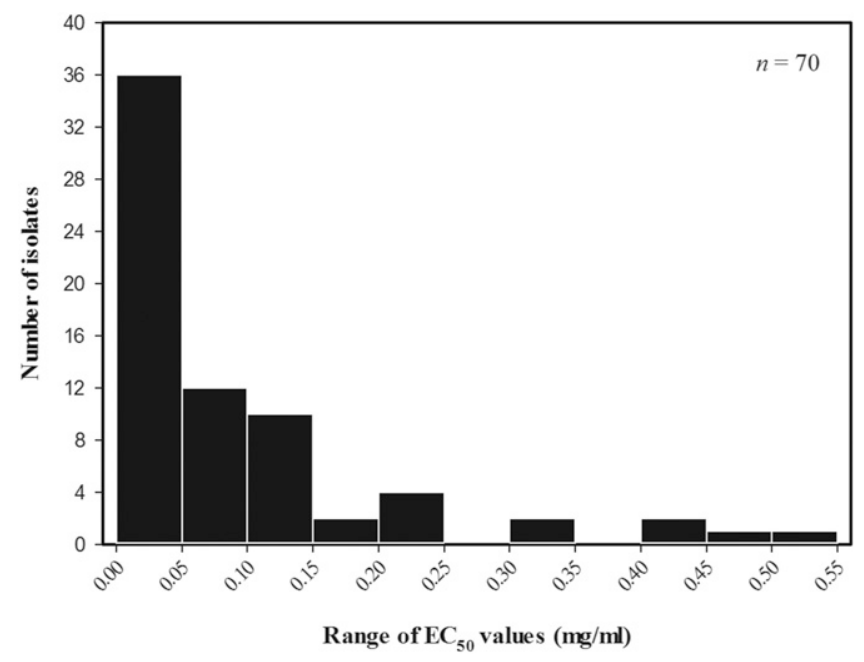

Fig. 1. Frequency distribution of effective concentration at which mycelial growth was inhibited by $50 \%\left(\mathrm{EC}_{50}\right)$ for 70 Botrytis cinerea baseline isolates to isofetamid. Fungicide sensitivity was determined using spiral gradient dilution (SDG) method. Isolates were collected from strawberry fruit from different areas in Florida and had never been exposed to isofetamid. Values on the $\mathrm{X}$-axis indicate the individual isolates grouped in $\mathrm{EC}_{50}$ ranges with intervals of $0.05 \mu \mathrm{g} / \mathrm{ml}$.
BioEdit version 7.0.5.3 (Hall 1999) was used to assemble sequences and Mega7 version 7.0.2.6 (Kumar et al. 2016) for translation and alignment.

Fruit assays. In vivo evaluations of isofetamid efficacy were conducted on strawberry fruit of 'Florida Radiance' with no prior exposure to the fungicide. Fruit with white to pinkish color were harvested from an experimental area at the GCREC, and the methodology described by Amiri et al. (2013) was followed for fruit preparation and inoculation. Prior to inoculation, fruit were sprayed with Kenja, a.i. isofetamid, at $1.2 \mathrm{ml} /$ liter until complete coverage of the fruit was achieved. Three moderately resistant $B$. cinerea isolates harboring the N230I mutation and two sensitive isolates were used for inoculation. Fruit were incubated in growth chambers at $23^{\circ} \mathrm{C}$ for 6 days, and BFR incidence was determined by the number of symptomatic fruit that were sprayed with isofetamid compared with the control sprayed with water. The experiment consisted of six fruit per isolate with four replications, and the assay was conducted twice. The conidial production was also evaluated on detached fruit following the protocol by Amiri et al. (2014). For this, conidia were collected using one cotton swab per fruit and placed in $1 \mathrm{ml}$ of sterile distilled water, and then counted using a hemacytometer.

Statistical analysis. Repeated experiments for phenotypic characterization and baseline sensitivity were combined after analysis of variance was tested using the generalized linear mixed model, and means were separated using Fisher's protected least significant difference (LSD). Analysis of variance was performed for data from in vivo evaluations of isofetamid for BFR incidence and conidial production, and means were separated using LSD test. All statistical analyses for this study were conducted using the SAS software (version 9.4; SAS Institute Inc.).

\section{Results}

Baseline sensitivity of $\boldsymbol{B}$. cinerea isolates to isofetamid. The $\mathrm{EC}_{50}$ values of isolates exposed to isofetamid ranged from 0.007 to $0.515 \mu \mathrm{g} / \mathrm{ml}$ (Fig. 1) with a mean value of $0.050 \mu \mathrm{g} / \mathrm{ml}$. Regardless of the relatively wide $\mathrm{EC}_{50}$ range, most of the baseline $\mathrm{EC}_{50}$ values $(51.4 \%)$ were below $0.050 \mu \mathrm{g} / \mathrm{ml}$ and $31.4 \%$ between 0.053 and $0.150 \mu \mathrm{g} / \mathrm{ml}$. EC S0 $_{5}$ values that were from 0.155 to $0.490 \mu \mathrm{g} / \mathrm{ml}$ represented $15.7 \%$ of the population, and only $1.4 \%$ ( 1 isolate) had an $\mathrm{EC}_{50}$ value higher than $0.500 \mu \mathrm{g} / \mathrm{ml}$. The $\mathrm{EC}_{50}$ values were over $0.155 \mu \mathrm{g} / \mathrm{ml}$ for isolates collected from 2005 through 2013 .

Phenotypic characterization of $\mathrm{SdhB}$ mutations in resistant isolates of $\boldsymbol{B}$. cinerea. Isolates 11-45 and 12-241 that were sensitive to boscalid and had no mutation on the $\mathrm{SdhB}$ were also $\mathrm{S}$ to isofetamid with $\mathrm{EC}_{50}$ values of 0.18 and $0.22 \mu \mathrm{g} / \mathrm{ml}$, respectively (Table 2). Isolates with mutations H272R (10-35, 11-67, 12-221, and 12-332) and $\mathrm{H} 272 \mathrm{Y}$ (12-65) were also characterized as S to isofetamid according to their corresponding $\mathrm{EC}_{50}$ values, 0.19, 0.30, 0.30, $0.26,0.01 \mu \mathrm{g} / \mathrm{ml}$. The isolates $12-450$ and $12-255$ harboring the mutation N230I with $\mathrm{EC}_{50}$ values of 1.46 and $4.79 \mu \mathrm{g} / \mathrm{ml}$ were characterized as MR. The $\mathrm{EC}_{50}$ values for isolates 11-62, 12-355, and 12-374 harboring the P225F mutation were greater than $500 \mu \mathrm{g} / \mathrm{ml}$, conferring high resistance to isofetamid. Three additional isolates, 17-94, 17-111, and 17-222, collected during the 2016-2017 season, showed $\mathrm{EC}_{50}$ values of $1.71,3.52$, and $3.70 \mu \mathrm{g} / \mathrm{ml}$, respectively, and were characterized as MR. These results match the monitoring using the conidial germination assay where these isolates were also characterized as MR.

Sensitivity of $\boldsymbol{B}$. cinerea isolates to SDHI fungicides. During the 2015-2016 season, boscalid resistance frequencies were $97.9 \%$ in isolates collected from Florida farms and $93.6 \%$ in isolates from nurseries (Fig. 2A). Resistance frequencies of isolates from Florida farms and nurseries were 33.3 and $33.5 \%$ for penthiopyrad, and 22.7 and $19.7 \%$ for fluopyram, respectively. Different results were observed for benzovindiflupyr sensitivity, in which the frequency of resistant isolates collected from strawberry farms was $31.2 \%$ compared with $20.2 \%$ for isolates from nurseries. Resistance to isofetamid was not observed in isolates from either location during 2015-2016. In the following season, 2016-2017, resistance frequency from Florida farms and nursery isolates for boscalid was 
94.6 and $85.7 \%$ (Fig. 2B), and for penthiopyrad was 95.8 and $92.9 \%$, respectively. Differences among isolates were observed for fluopyram and benzovindiflupyr depending on their origin. The resistance frequency of isolates from strawberry farms to fluopyram was $56.6 \%$, whereas only $14.3 \%$ of the nursery isolates were resistant. In the case of benzovindiflupyr, the respective frequencies were 36.1 and $4.3 \%$. In 2016-2017, resistance to isofetamid was found in only $1.8 \%$ of isolates from Florida farms.

Phenotypic characterization of 2015-2016 isolates (Fig. 2A) resulted in a small population of $B$. cinerea being $\mathrm{S}(4.6 \%)$ and MR (1.8\%) to boscalid, whereas the remaining $93.6 \%$ were HR. Penthiopyrad phenotypic characterization frequencies were $15.8 \% \mathrm{HR}$, $17.6 \% \mathrm{MR}$, and $66.6 \% \mathrm{~S}$. Results for fluopyram showed frequencies of $79 \% \mathrm{~S}, 1.3 \% \mathrm{MR}$, and $9.7 \% \mathrm{HR}$. Similar results were obtained for benzovindiflupyr with frequencies of $75.1 \% \mathrm{~S}, 17 \% \mathrm{MR}$, and $7.9 \%$ HR. All 329 isolates were $S$ to isofetamid, indicating the fungicide inhibited $B$. cinerea spore germination of isolates collected during the first evaluated season. Isolates with a high level of resistance $(91.5 \%)$ were observed for boscalid in the following season, 2016-2017, and only $8.1 \%$ were S (Fig. 2B). The MR (56.8\%) and HR $(38.1 \%)$ isolates were observed for penthiopyrad, while $\mathrm{S}$ isolates were at $5.1 \%$. Isolates with $S$ phenotype to fluopyram were
$55.9 \%$ of the population tested during this season, whereas HR isolates were at $35.2 \%$. Isolates considered S, MR, and HR to benzovindiflupyr were $73.3,20.8$, and $5.9 \%$, respectively. Resistance to isofetamid was first observed during the second season, with only $1.3 \%$ of the population classified as MR and the remaining $98.7 \%$ as $\mathrm{S}$.

Fungicide resistance (FR) for $B$. cinerea isolates to the five SDHIs was evaluated for the 2015-2016 and 2016-2017 seasons combined (Fig. 3). Resistance to one fungicide, boscalid, was observed in 198 isolates representing $35 \%$ of the population tested $(n=565)$, and eight isolates corresponding to $1.4 \%$ for penthiopyrad. The frequencies of isolates resistant to two fungicides (2FR) was $22.1 \%$ for boscalid and penthiopyrad, and $1.2 \%$ for boscalid and benzovindiflupyr. Resistance to three fungicides (3FR) always occurred for boscalid, penthiopyrad, and benzovindiflupyr or fluopyram with 5 and $11.2 \%$, respectively. B. cinerea-resistant isolates to four (4FR) SDHIs (boscalid, penthiopyrad, benzovindiflupyr, and fluopyram) were $18.9 \%$, whereas $0.5 \%$, three isolates, were resistant to all five fungicides (5FR), including isofetamid.

Characterization of $\mathrm{SdhB}$ mutations in resistant isolates of B. cinerea. Sequences from the $\mathrm{SdhB}$ region were aligned to a $B$. cinerea isolate without mutations (GenBank accession KR866382.1).
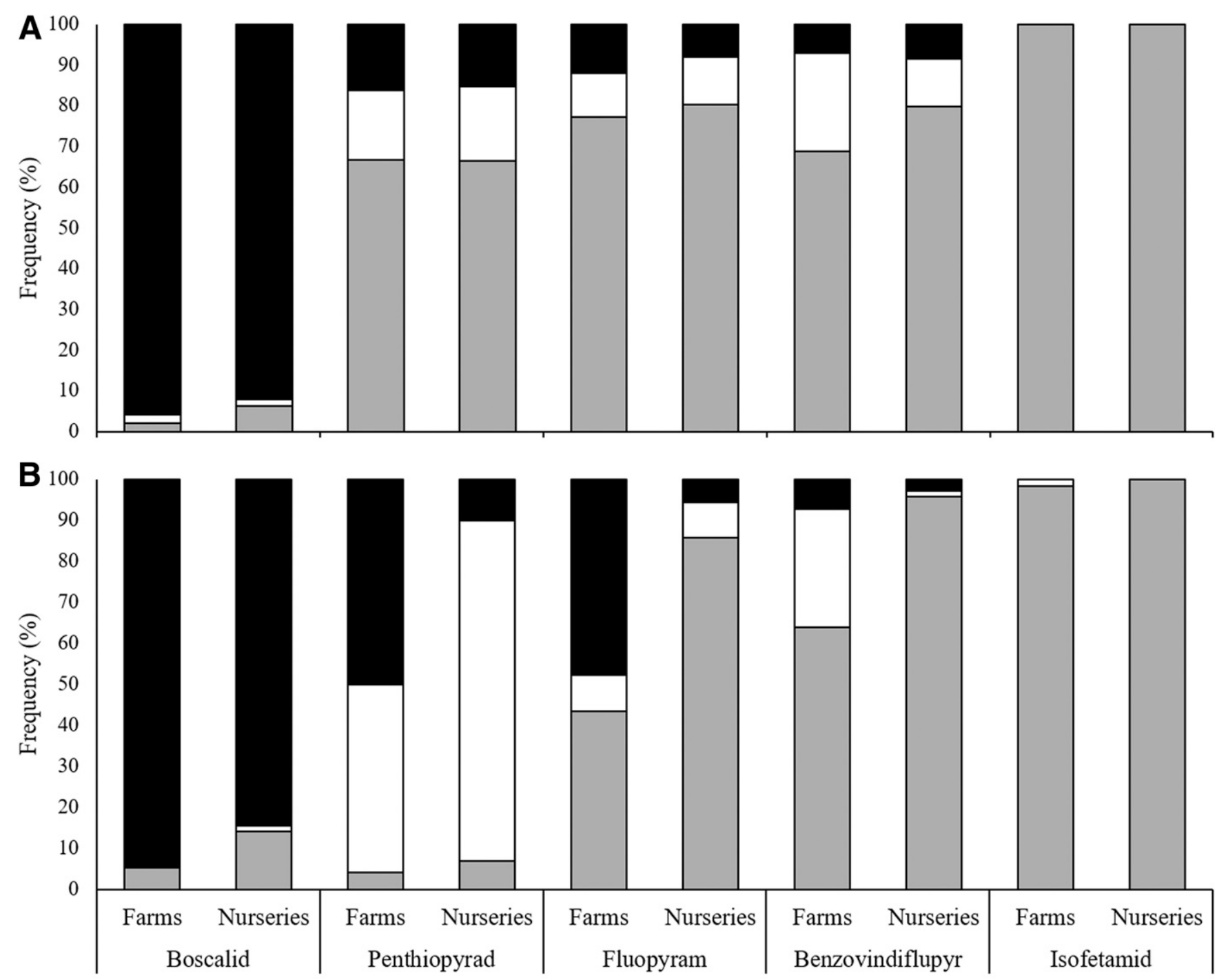

$\square \mathrm{S} \square \mathrm{MR} \mathbf{\mathrm { HR }}$

Fig. 2. Frequency of fungicide sensitivity of Botrytis cinerea isolates collected from strawberry nurseries and Florida fields during 2015-2016 (A) and 2016-2017 (B) strawberry seasons to five succinate dehydrogenase inhibitors (SDHI) fungicides. The fungicide concentrations used were 2 or $5 \mu \mathrm{g} / \mathrm{ml}$ of boscalid (Endura) and fluopyram (Luna Privilege), and 1 and $5 \mu \mathrm{g} / \mathrm{ml}$ of penthiopyrad (Fontelis), benzovindiflupyr (Aprovia, not registered for strawberry), and isofetamid (Kenja) each. Conidial germination data were used to determine frequency of resistance to the fungicides in the evaluated nurseries and Florida fields. $S=$ sensitive, $M R=$ moderately resistant, HR $=$ highly resistant. 
The translated amino acid sequence revealed a substitution of asparagine by isoleucine at codon 230 in the three isolates (17-94, 17-111, and 17-222) found to be moderately resistant to isofetamid collected during 2016-2017 (Table 3). Sequences for the 20 arbitrarily selected resistant isolates to other SDHIs from both seasons identified the mutations H272R and N230I in seven and 13 isolates, respectively (Table 3 ).

Fruit assays. Preventive application of isofetamid effectively controlled $\mathrm{S}$ isolates (05-26 and 17-97) but failed to control isolates with N230I mutations (Table 4). In comparison with S isolates, BFR incidence was significantly higher on MR isolates 17-94, 17-111, and 17-222 with 55.6, 77.0, and 72.1\%, respectively. A significant difference was also observed in the conidial inhibition between $S$ and MR isolates. Conidial production was completely inhibited on $\mathrm{S}$ isolates, whereas on isolates harboring the N230I mutation, the inhibition ranged from 70.7 to $91.3 \%$ (Table 4).

\section{Discussion}

Isofetamid is the latest broad-spectrum member of the SDHIs registered for use on strawberry in Florida. Other SDHIs available for strawberry include boscalid, penthiopyrad, fluxapyroxad, and fluopyram. In this study, isofetamid showed high efficacy inhibiting growth of B. cinerea isolates resistant to the other SDHIs. However, a few isolates resistant to isofetamid that were also resistant to boscalid, penthiopyrad, and fluopyram appeared during the second season of monitoring. It has been shown in previous studies that resistance levels to penthiopyrad are similar to fluxapyroxad (Amiri et al. 2014). Thus, we chose to use only penthiopyrad in this study.

The initial step to monitor for the selection of fungicide resistance in pathogen populations is to determine the baseline sensitivity using isolates collected prior to widespread use of the fungicide. To our knowledge, this is the first study to determine the baseline sensitivity of $B$. cinerea isolates from strawberry to isofetamid, a thiophenecarboxamide fungicide (Xiong et al. 2015). Our results using isolates collected before isofetamid registration in 2015 showed a relatively wide range of $\mathrm{EC}_{50}$ values. However, $83 \%$ of the strawberry isolates tested were at the lower end of the baseline $(\leq 0.15 \mu \mathrm{g} / \mathrm{ml})$, similar to mycelium growth inhibition assays reported for isofetamid baseline in grapevine B. cinerea isolates (Piqueras et al. 2014).

Baselines with wide $\mathrm{EC}_{50}$ ranges have also been reported for other SDHI fungicides such as penthiopyrad, fluopyram, and boscalid with B. cinerea isolates from table grape (Vitale et al. 2016) and

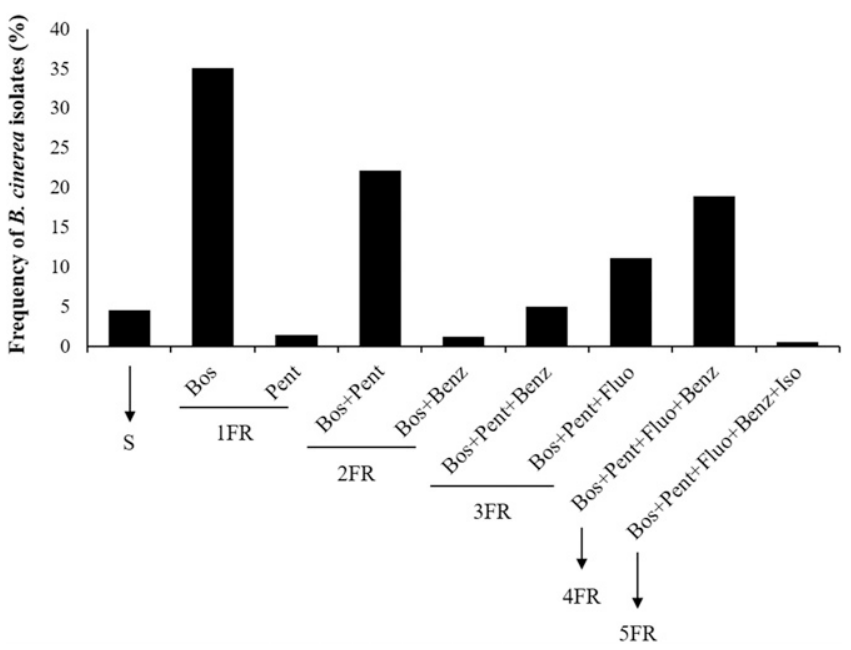

Fig. 3. Frequency of Botrytis cinerea isolates $(n=565)$ collected during two strawberry seasons from different nurseries and Florida fields, showing fungicide resistance (FR) to five succinate dehydrogenase inhibitor (SDHI) fungicides Boscalid, Penthiopyrad, Fluopyram, Benzovindiflupyr, and Isofetamid represented as Bos, Pent, Fluo, Benz, and Iso, respectively. $\mathrm{S}=$ sensitive, $1 \mathrm{FR}=$ resistance to one fungicide, $2 \mathrm{FR}=$ resistance to two fungicides, $3 \mathrm{FR}=$ resistance to three fungicides, $4 \mathrm{FR}=$ resistance to four fungicides, and $5 F R=$ resistance to five fungicides. for other pathogens such Alternaria alternata (Avenot et al. 2014). The relatively wide $\mathrm{EC}_{50}$ ranges can be related to genetic variability resulting in different responses among pathogen populations to the fungicide. The number of isolates can also be a factor for a wide sensitivity range, although Thomas et al. (2012) previously reported a baseline sensitivity in Didymella bryoniae using a similar number of isolates $(n=71)$ as used in our study but obtained narrow $\mathrm{EC}_{50}$

Table 3. Identification of succinate dehydrogenase subunit B (SDH-B) mutations in Botrytis cinerea isolates

\begin{tabular}{|c|c|c|c|c|}
\hline \multirow[b]{2}{*}{ Isolate $^{\mathrm{z}}$} & \multicolumn{2}{|c|}{ Phenotype $^{x}$} & \multicolumn{2}{|c|}{ Translated protein sequences ${ }^{y}$} \\
\hline & Boscalid & Isofetamid & 230 & 272 \\
\hline $15-1000$ & HR & $S$ & PSYWWNSEEYL & MSLYRCRTILNCS \\
\hline 17-02 & HR & S & PSYWWNSEEYL & MSLYRCRTILNCS \\
\hline $17-51$ & HR & $\mathrm{S}$ & PSYWWNSEEYL & MSLYRCRTILNCS \\
\hline $17-63$ & HR & $\mathrm{S}$ & PSYWWNSEEYL & MSLYRCRTILNCS \\
\hline $17-103$ & HR & S & PSYWWNSEEYL & MSLYRCRTILNCS \\
\hline $17-109$ & HR & $\mathrm{S}$ & PSYWWNSEEYL & MSLYRCRTILNCS \\
\hline $17-241$ & HR & S & PSYWWNSEEYL & MSLYRCRTILNCS \\
\hline $15-1025$ & HR & S & PSYWWISEEYL & MSLYRCHTILNCS \\
\hline $15-1063$ & HR & S & PSYWWISEEYL & MSLYRCHTILNCS \\
\hline $16-32$ & HR & $\mathrm{S}$ & PSYWWISEEYL & MSLYRCHTILNCS \\
\hline $16-58$ & HR & $\mathrm{S}$ & PSYWWISEEYL & MSLYRCHTILNCS \\
\hline $16-88$ & HR & $\mathrm{S}$ & PSYWWISEEYL & MSLYRCHTILNCS \\
\hline $16-94$ & HR & S & PSYWWISEEYL & MSLYRCHTILNCS \\
\hline $17-10$ & HR & S & PSYWWISEEYL & MSLYRCHTILNCS \\
\hline $17-39$ & HR & $\mathrm{S}$ & PSYWWISEEYL & MSLYRCHTILNCS \\
\hline 17-94 & HR & MR & PSYWWISEEYL & MSLYRCHTILNCS \\
\hline $17-99$ & HR & S & PSYWWISEEYL & MSLYRCHTILNCS \\
\hline $17-111$ & HR & MR & PSYWWISEEYL & MSLYRCHTILNCS \\
\hline $17-158$ & HR & S & PSYWWISEEYL & MSLYRCHTILNCS \\
\hline $17-211$ & HR & S & PSYWWISEEYL & MSLYRCHTILNCS \\
\hline $17-222$ & HR & MR & PSYWWISEEYL & MSLYRCHTILNCS \\
\hline $17-223$ & HR & $\mathrm{S}$ & PSYWWISEEYL & MSLYRCHTILNCS \\
\hline $17-234$ & HR & $\mathrm{S}$ & PSYWWISEEYL & MSLYRCHTILNCS \\
\hline
\end{tabular}

${ }^{x}$ Resistance phenotypes obtained in this study for boscalid and isofetamid. $\mathrm{S}=$ sensitive, $\mathrm{MR}=$ moderately resistant, and $\mathrm{HR}=$ highly resistant.

${ }^{y}$ Fragments of the translated protein sequences after alignment showing replacement of asparagine $(\mathrm{N})$ by isoleucine (I) and histidine $(\mathrm{H})$ by arginine (R) at codons 230 and 272 , respectively.

${ }^{\mathrm{z}}$ B. cinerea isolates collected during the 2015-2016 and 2016-2017 strawberry seasons from different strawberry nurseries and Florida farms.

Table 4. Efficacy of isofetamid on Botrytis cinerea isolates with different sensitivity levels

\begin{tabular}{lcccc}
\hline Isolate $^{\mathbf{v}}$ & Genotype $^{\mathbf{w}}$ & Phenotype $^{\mathbf{x}}$ & $\begin{array}{c}\text { Disease } \\
\text { incidence }(\%)\end{array}$ & $\begin{array}{c}\text { Conidial } \\
\text { inhibition }(\%)^{\mathbf{z}}\end{array}$ \\
\hline $05-26$ & WT & $\mathrm{S}$ & $0.0 \mathrm{a}$ & $100.0 \mathrm{a}$ \\
$17-97$ & & $\mathrm{~S}$ & $0.0 \mathrm{a}$ & $100.0 \mathrm{a}$ \\
$17-94$ & \multirow{2}{*}{ N230I } & MR & $55.6 \mathrm{~b}$ & $89.9 \mathrm{~b}$ \\
$17-222$ & & MR & $72.1 \mathrm{bc}$ & $91.3 \mathrm{bc}$ \\
$17-111$ & & MR & $77.0 \mathrm{c}$ & $70.7 \mathrm{~cd}$ \\
\hline
\end{tabular}

${ }^{v}$ Isolates collected before and after isofetamid registration in 2015 in Florida. Isolates 17-94, 17-111, and 17-222 were found to be resistant in the fungicide sensitivity screening in this study.

${ }^{\text {w }}$ Mutation N230I in the SDH-B subunit. WT = wild type.

$x$ Resistance phenotypes: $\mathrm{S}=$ sensitive and $\mathrm{MR}=$ moderately resistant.

y Percentage of infected fruit showing Botrytis fruit rot symptoms relative to nontreated control. Data consisted of the mean of 48 values for each isolate from two experimental assays. Values followed by the same letter in the same column are not significantly different after analysis of variance and least significant difference test at $P \leq 0.05$.

z Percentage of conidial inhibition by isofetamid relative to nontreated control. Data consisted of the mean 24 values for each isolate obtained from two experimental assays. Values followed by the same letter in the same column are not significantly different after analysis of variance and least significant difference tests at $P \geq 0.05$. 
ranges for penthiopyrad and boscalid. Thus, the high genetic variability of $B$. cinerea (Williamson et al. 2007) might be the main contributing factor for the wide $\mathrm{EC}_{50}$ range of our baseline isolates.

The first SDHI fungicides were released in 1966 (Leroux 2007), but a large spectrum of molecules considered highly effective against BFR were released after 2003. The rapid increase of SDHI use in combination with their mode of action targeting a single site makes them susceptible to selection for resistance. Different levels of fungicide resistance to the first broad-spectrum SDHI, boscalid, was previously reported to be conferred by the mutations H272R, H272Y, $\mathrm{N} 230 \mathrm{I}$, and $\mathrm{P} 225 \mathrm{~F}$ in $\mathrm{B}$. cinerea isolates from Florida strawberry fields (Amiri et al. 2014). Esterio et al. (2015) and Yin et al. (2011) found the same mutations on $B$. cinerea isolates resistant to boscalid from table grape in Chile and apple in Washington, respectively. Boscalid has been used for the longest time among the SDHIs registered on strawberry, and resistance to this compound was observed soon after its registration (Amiri et al. 2014). For this reason, boscalid was used to compare SdhB mutations in this study.

Boscalid completely failed to inhibit mycelial growth of isolates harboring $\mathrm{P} 225 \mathrm{~F}$ mutation conferring high $\mathrm{EC}_{50}$ values on in vitro assays (Amiri et al. 2014). Similar results were obtained for other SDHIs such as benodanil, bizafen, fenfuram, isopyrazam, fluxapyroxad, penthiopyrad, and fluopyram (Amiri et al. 2014; Veloukas et al. 2013). The P225F mutation also conferred high levels of resistance to isofetamid with $\mathrm{EC}_{50}$ values over $500 \mu \mathrm{m} / \mathrm{ml}$. Our results agree with previous findings indicating that this mutation is a great threat to the SDHI fungicides; however, this substitution has rarely been detected in field isolates (Veloukas et al. 2014). The mutations H272R and H272Y confer moderate to high levels of resistance to boscalid (Lalève et al. 2014; Veloukas et al. 2011) and are usually the most frequently found in $B$. cinerea strawberry isolates as reported by Fernández-Ortuño et al. (2012) and Leroux et al. (2010). The lack of fitness penalties especially for H272R represent a possible explanation for their persistence within populations (Veloukas et al. 2014), but these mutations failed to confer resistance to isofetamid in $B$. cinerea isolates in our study. Interestingly, N230I, a mutation of lower occurrence, showed moderate resistance in five isolates that carried the mutation. This contrasts with Veloukas et al. (2013), who reported in vitro growth inhibition of isolates with N230I mutation using fluopyram and other SDHIs, but isofetamid was not tested. Furthermore, Amiri et al. (2014) found that N230I conferred high to very high resistance to boscalid and fluxapyroxad, and different levels of resistance to penthiopyrad and fluopyram from moderate to very high resistance. These results support ours, considering that this mutation was found in resistant isolates to relatively new SDHI fungicides at the time, excluding boscalid.

In accordance with our $\mathrm{SdhB}$ phenotypic characterization, isolates with moderate resistance to isofetamid found in the 2016-2017 season were confirmed to have a substitution at codon 230 of asparagine by isoleucine (N230I). On average, these isolates showed a BFR incidence of $68.2 \%$ on strawberry sprayed with isofetamid and $84.0 \%$ inhibition of conidial production. Isolates with the same mutation caused $100 \%$ disease when sprayed with boscalid, fluopyram, and fluxapyroxad with the corresponding conidial inhibition percentages of 71.9, 57.4, and 72.2\% (Amiri et al. 2014). Additional sequencing of the SdhB subunit for 20 randomly selected resistant isolates from the monitoring of resistance to SDHIs also identified the N230I mutation in $65 \%$ of the isolates, but they did not always confer resistance to isofetamid. Thus, based on these results, we hypothesize that the ability of $B$. cinerea to develop more than one mutation to an independently targeted site (Veloukas et al. 2014) might be a contributing factor for N230I mutation to confer resistance to isofetamid. Another interesting observation based on our results is that the resistant populations might be undergoing a genotypic predominance shift where $\mathrm{H} 272 \mathrm{R} / \mathrm{Y}$ is decreasing while N230I is increasing in Florida fields, which might explain the increasing resistance frequencies to fluopyram. However, future investigation is needed to better understand the effect of this mutation on fungicide sensitivity.

Monitoring of SDHI fungicide resistance frequencies was conducted for isolates collected from strawberry nurseries and Florida farms for two consecutive seasons. Isofetamid, the newest SDHI fungicide, showed no resistance during 2015-2016 and 1.8\% $(n=3)$ frequency of moderately resistant phenotype for the following season, but only on isolates collected from Florida fields. High frequency of sensitivity (100\%) to this fungicide was also reported by Hu et al. (2018) against $B$. cinerea and $B$. fragariae isolates resistant to fungicides of one, two, three, four, or five chemical classes, likewise to other studies showing no resistance on $B$. fragariae (Dowling et al. 2018) and B. mali (Cosseboom et al. 2018). Furthermore, isofetamid has been reported to control $B$. cinerea effectively on table grape in Chile based on in vitro assays (Piqueras et al. 2014). The high in vitro effectiveness of isofetamid against Botrytis spp. according to our study confirms its high field efficacy compared with other SDHI fungicides (Cordova et al. 2015). Isofetamid is the second SDHI carrying a phenethylamide derivative (Jeanmart et al. 2016), which might explain the effective control observed in our and in other studies. However, an increase of resistance frequency was observed in our study to fluopyram, the first SDHI with the same characteristics as isofetamid. Therefore, the limited use of isofetamid is essential to preserve its efficacy.

In the second season (2016-2017), penthiopyrad and fluopyram resistance was observed at high frequencies in the two locations and only in Florida farms, respectively. Overall, a high frequency of $B$. cinerea resistance was observed to boscalid (93.9\%) similar to that reported by Amiri et al. $(2013,2014)$ in Florida fields $(85.4$ and $100 \%$ ) and by Oliveira et al. (2017) for nursery isolates (89.6\%). Our results also agree with $B$. cinerea boscalid resistance on strawberry in the Carolinas (Fernández-Ortuño et al. 2012) and other hosts such as raspberry, grapevine, sweet cherry, and ornamental flowers in Germany (Rupp et al. 2017). However, Hu et al. (2016) found a much lower resistance frequency to boscalid in a study involving 12 states, not including Florida. The contradiction among studies could indicate the prevalence of boscalid resistance in Florida fields despite the fact that this fungicide is no longer used by commercial growers. On the other hand, this discrepancy could be explained by the different method used to conduct the experiments and the use of symptomatic strawberry fruit in our study versus asymptomatic flowers by $\mathrm{Hu}$ et al. (2016) for B. cinerea isolation. The same authors also reported very low resistance frequencies for penthiopyrad and fluopyram ( $<8 \%$ for each), similar to the results of Oliveira et al. (2017), which contradicts the corresponding frequencies obtained in this study, 59.1 and $30.6 \%$, respectively. A previous report by Amiri et al. (2014) concluded that penthiopyrad rapidly selects for resistance in $B$. cinerea, which could explain our results in comparison with previous studies and the difference observed within the seasons evaluated.

Fluopyram resistance in our study was relatively high compared with that mentioned above, but its efficacy against BFR is higher compared with penthiopyrad (Zuniga et al. 2017). However, based on our results, resistance management of this fungicide needs improvement to preserve its efficacy. Benzovindiflupyr, an SDHI fungicide not yet registered for Botrytis fruit rot control on strawberry was also evaluated for resistance to $B$. cinerea. Overall frequency of resistance to this fungicide was low $(25.7 \%)$ based on the conidial germination assay, indicating high activity against the pathogen. Our results agree with those of Hu et al. (2016) with the same effect on mycelial growth of strawberry isolates and to both conidial and mycelial inhibition of other pathogens such as Venturia inaequalis (Villani et al. 2016).

Fungicide-resistant (FR) phenotypes among the SDHI tested were also observed in this study. Resistant isolates to one fungicide were found at higher frequency (35\%) compared with 2FR, 3FR, and 4FR, and $5 \mathrm{FR}$ isolates were observed at very low frequencies $(0.5 \%)$. A previous study with $B$. cinerea isolates from nursery transplants reported 2FR occurred most commonly followed by 3FR (Oliveira et al. 2017). However, Amiri et al. (2013) found 2FR was the second highest after 3FR in $B$. cinerea isolates collected from fruiting fields. In agreement with these authors, $B$. cinerea resistance to more than one fungicide seems to occur at a higher rate. This might be due to the ability of the pathogen to develop more than one mutation related to a specific targeted site (Veloukas et al. 2014). 
This study emphasizes the importance of resistance management of old and new SDHI fungicides, considering this group represents one of the most effective in managing BFR. Single-site fungicides should always be alternated or tank-mixed with multisite fungicide (Amiri et al. 2019) to minimize the selection of resistant populations. Reducing the use of fungicides with rapid selection for resistance such as penthiopyrad and limiting applications of other single-site fungicides such as fluopyram and isofetamid to only during bloom periods or following the Strawberry Advisory System (Cordova et al. 2017a; Pavan et al. 2017), and restricting applications in nurseries, can help preserve the efficacy of these fungicides. Finally, periodic evaluation of SDHI fungicides is advised to monitor resistance frequencies and predominant genotypes of SdhB mutations in B. cinerea from strawberry fields.

\section{Acknowledgment}

We thank Leandro Cordova, Juliana Baggio, Eduardo Suarez, Erika Zielinski, Robiel Vieira, and Mayara Bolognesi, from the University of Florida - Gulf Coast Research and Education Center, for technical assistance.

\section{Literature Cited}

Amiri, A., Heath, S., and Peres, N. 2013. Phenotypic characterization of multifungicide resistance in Botrytis cinerea isolates from strawberry fields in Florida. Plant Dis. 97:393-401.

Amiri, A., Heath, S. M., and Peres, N. A. 2014. Resistance to fluopyram, fluxapyroxad, and penthiopyrad in Botrytis cinerea from strawberry. Plant Dis. 98:532-539.

Amiri, A., and Peres, N. A. 2014. Diversity in the erg27 gene of Botrytis cinerea field isolates from strawberry defines different levels of resistance to the hydroxyanilide fenhexamid. Plant Dis. 98:1131-1137.

Amiri, A., Zuniga, A. I., Cordova, L., and Peres, N. A. 2019. The importance of selecting appropriate rotation and tank-mix partners for novel SDHIs to enhance Botrytis fruit rot control in strawberry. Plant Dis. 103:729-736.

Avenot, H. F., Van Den Biggelaar, H., Morgan, D. P., Moral, J., Joosten, M., and Michailides, T. 2014. Sensitivities of baseline isolates and boscalid-resistant mutants of Alternaria alternata from pistachio to fluopyram, penthiopyrad, and fluxapyroxad. Plant Dis. 98:197-205.

Bulger, M., Ellis, M., and Madden, L. 1987. Influence of temperature and wetness duration on infection of strawberry flowers by Botrytis cinerea and disease incidence of fruit originating from infected flowers. Phytopathology 77: 1225-1230.

Cordova, L., Zuniga, A. I., Mertely, J., and Peres, N. A. 2015. Evaluation of products for control of Botrytis fruit rot in annual strawberry, 2014-15. Plant Dis. Manag. Rep. 9:SMF020.

Cordova, L. G., Amiri, A., and Peres, N. A. 2017a. Effectiveness of fungicide treatments following the Strawberry Advisory System for control of Botrytis fruit rot in Florida. Crop Prot. 100:163-167.

Cordova, L. G., Ellis, M. A., Wilson, L. L., Madden, L. V., and Peres, N. A. 2018. Evaluation of the Florida Strawberry Advisory System for control of Botrytis and Anthracnose fruit rots in Ohio. Plant Health Prog. 19:182-187.

Cordova, L. G., Madden, L. V., Amiri, A., Schnabel, G., and Peres, N. A. 2017b. Meta-analysis of a web-based disease forecast system for control of anthracnose and Botrytis fruit rots of strawberry in southeastern United States. Plant Dis. 101:1910-1917.

Cosseboom, S., Ivors, K., Schnabel, G., and Holmes, G. 2018. First report of Botrytis mali causing gray mold on strawberry in California. Plant Dis. 102:679.

Dowling, M. E., Hu, M.-J., and Schnabel, G. 2018. Fungicide resistance in Botrytis fragariae and species prevalence in the mid-Atlantic United States. Plant Dis. 102:964-969.

Esterio, M., Araneda, M., Román, A., Pizarro, L., Copier, C., and Auger, J. 2015. First report of boscalid resistant Botrytis cinerea isolates carrying the mutations H272R, H272Y, P225L, and P225H from table grape in Chile. Plant Dis. 99:891.

Fernández-Ortuño, D., Chen, F., and Schnabel, G. 2012. Resistance to pyraclostrobin and boscalid in Botrytis cinerea isolates from strawberry fields in the Carolinas. Plant Dis. 96:1198-1203.

Förster, H., Kanetis, L., and Adaskaveg, J. E. 2004. Spiral gradient dilution, a rapid method for determining growth responses and 50\% effective concentration values in fungus-fungicide interactions. Phytopathology 94:163-170.

FRAC. 2017. Fungicide Resistance Action Committee (FRAC) Code List 2017: Fungicides sorted by mode of action (including FRAC Code numbering). Crop Life International, Brussels, Belgium. Online document available at: https://www.frac.info.

Hall, T. A. 1999. BioEdit: A user-friendly biological sequence alignment editor and analysis program for windows 95/98/NT. Nucleic Acids Symp. Ser. 41:95-98.

Hu, M.-J., Dowling, M. E., and Schnabel, G. 2018. Genotypic and phenotypic variations in Botrytis spp. isolates from single strawberry flowers. Plant Dis. 102:179-184.
Hu, M.-J., Fernández-Ortuño, D., and Schnabel, G. 2016. Monitoring resistance to SDHI fungicides in Botrytis cinerea from strawberry fields. Plant Dis. 100: 959-965.

Jeanmart, S., Edmunds, A. J., Lamberth, C., and Pouliot, M. 2016. Synthetic approaches to the 2010-2014 new agrochemicals. Bioorg. Med. Chem. 24:317-341

Kumar, S., Stecher, G., and Tamura, K. 2016. MEGA7: Molecular evolutionary genetics analysis version 7.0 for bigger datasets. Mol. Biol. Evol. 33: 1870-1874

Kumari, S., Tayal, P., Sharma, E., and Kapoor, R. 2014. Analyses of genetic and pathogenic variability among Botrytis cinerea isolates. Microbiol. Res. 169: $862-872$.

Lalève, A., Gamet, S., Walker, A. S., Debieu, D., Toquin, V., and Fillinger, S. 2014. Site-directed mutagenesis of the P225, N230 and H272 residues of succinate dehydrogenase subunit B from Botrytis cinerea highlights different roles in enzyme activity and inhibitor binding. Environ. Microbiol. 16:2253-2266.

Legard, D. E., MacKenzie, S. J., Mertely, J. C., Chandler, C. K., and Peres, N. A 2005. Development of a reduced use fungicide program for control of Botrytis fruit rot on annual winter strawberry. Plant Dis. 89:1353-1358.

Leroch, M., Plesken, C., Weber, R. W., Kauff, F., Scalliet, G., and Hahn, M. 2013 Gray mold populations in German strawberry fields are resistant to multiple fungicides and dominated by a novel clade closely related to Botrytis cinerea. Appl. Environ. Microbiol. 79:159-167.

Leroux, P. 2007. Chemical control of Botrytis and its resistance to chemical fungicides. Pages 195-222 in: Botrytis: Biology, Pathology and Control. Y. Elad, B. Williamson, P. Tudzynski, and N. Delen, eds. Springer, Dordrecht.

Leroux, P., Gredt, M., Leroch, M., and Walker, A.-S. 2010. Exploring mechanisms of resistance to respiratory inhibitors in field strains of Botrytis cinerea, the causal agent of gray mold. Appl. Environ. Microbiol. 76:6615-6630.

Mertely, J. C., Oliveira, M. S., and Peres, N. A. 2018. Botrytis fruit rot or gray mold of strawberry. EDIS Plant Pathology Department, Florida Cooperative Extension Service, Institute of Food and Agricultural Sciences (IFAS) University of Florida, Gainesville, FL.

Oliveira, M. S., Amiri, A., Zuniga, A. I., and Peres, N. A. 2017. Sources of primary inoculum of Botrytis cinerea and their impact on fungicide resistance development in commercial strawberry fields. Plant Dis. 101:1761-1768.

Pavan, W., Clyde, W. F., Cordova, L. G., and Peres, N. A. 2017. The Strawberry Advisory System: A web-based decision support tool for timing fungicide applications in strawberry. EDIS Plant Pathology Department, Florida. Cooperative Extension Service, Institute of Food and Agricultural Sciences, University of Florida, Gainesville, FL.

Piqueras, C., Latorre, B., and Torres, R. 2014. Effectiveness of isofetamid, a new succinate dehydrogenase inhibitor fungicide, in the control of grapevine gray mold. Cienc. Investig. Agrar. 41:365-374.

Rupp, S., Weber, R. W., Rieger, D., Detzel, P., and Hahn, M. 2017. Spread of Botrytis cinerea strains with multiple fungicide resistance in German horticulture. Front. Microbiol. 7:2075.

Sierotzki, H., and Scalliet, G. 2013. A review of current knowledge of resistance aspects for the next-generation succinate dehydrogenase inhibitor fungicides. Phytopathology 103:880-887.

Thomas, A., Langston, D., Jr., and Stevenson, K. 2012. Baseline sensitivity and cross-resistance to succinate-dehydrogenase-inhibiting and demethylationinhibiting fungicides in Didymella bryoniae. Plant Dis. 96:979-984.

Veloukas, T., Kalogeropoulou, P., Markoglou, A., and Karaoglanidis, G. 2014. Fitness and competitive ability of Botrytis cinerea field isolates with dual resistance to SDHI and QoI fungicides, associated with several sdh B and the cyt b G143A mutations. Phytopathology 104:347-356.

Veloukas, T., Leroch, M., Hahn, M., and Karaoglanidis, G. S. 2011. Detection and molecular characterization of boscalid-resistant Botrytis cinerea isolates from strawberry. Plant Dis. 95:1302-1307.

Veloukas, T., Markoglou, A. N., and Karaoglanidis, G. S. 2013. Differential effect of SdhB gene mutations on the sensitivity to SDHI fungicides in Botrytis cinerea. Plant Dis. 97:118-122.

Villani, S. M., Ayer, K., and Cox, K. D. 2016. Molecular characterization of the sdhB gene and baseline sensitivity to penthiopyrad, fluopyram, and benzovindiflupyr in Venturia inaequalis. Plant Dis. 100:1709-1716.

Vitale, A., Panebianco, A., and Polizzi, G. 2016. Baseline sensitivity and efficacy of fluopyram against Botrytis cinerea from table grape in Italy. Ann. Appl. Biol. 169:36-45.

Weber, R. W., and Hahn, M. 2011. A rapid and simple method for determining fungicide resistance in Botrytis. J. Plant Dis. Prot. 118:17-25.

Williamson, B., Tudzynski, B., Tudzynski, P., and van Kan, J. A. 2007. Botrytis cinerea: The cause of grey mould disease. Mol. Plant Pathol. 8:561-580.

Xiong, L., Shen, Y.-Q., Jiang, L.-N., Zhu, X.-L., Yang, W.-C., Huang, W., and Yang, G.-F. 2015. Succinate dehydrogenase: An ideal target for fungicide discovery. Pages 175-194 in: Discovery and Synthesis of Crop Protection Products. ACS Publications.

Yin, Y., Kim, Y., and Xiao, C. 2011. Molecular characterization of boscalid resistance in field isolates of Botrytis cinerea from apple. Phytopathology 101:986-995

Zuniga, A. I., Cordova, L., Mertely, J., and Peres, N. A. 2017. Evaluation of fungicide products to control Botrytis fruit rot in annual strawberry, 2016-17. Plant Dis. Manag. Rep. 11:SMF029. 